\title{
Superoxide Anion Release by Polymorphonuclear Leukocytes in Whole Blood of Newborns and Mothers during the Peripartal Period
}

\author{
GIUSEPPE BUONOCORE, DINO GIOIA, MARCELLO DE FILIPPO, ENRICO PICCIOLINI, \\ AND RODOLFO BRACCI
}

\author{
Division of Neonatology and Neonatal Intensive Care Unit, and Department of Obstetrics and
} Gynaecology, University of Siena, Siena, Italy

\begin{abstract}
ABST whole blood of mothers in the peripartal period and in neonates. Blood samples from 14 mothers undergoing vaginal delivery (VD) were tested at the beginning of labor, during labor, after delivery, and $4 \mathrm{~d}$ after delivery. Nine mothers undergoing elective cesarean section (ECS) were tested before anesthesia, after extraction of the fetus, and $4 \mathrm{~d}$ later. Seventy-two healthy, full-term newborn infants were examined at birth and on the fourth day of life. Red cell glutathione peroxidase, catalase, glutathione reductase, and superoxide dismutase activities were also measured at birth and on the fourth day of life in 26 of the 72 neonates. Higher $\mathrm{O}_{2}{ }^{-}$levels were detected in mothers undergoing VD compared with ECS $(p<0.05)$. A significant decrease was detected in zymosan-stimulated $\cdot \mathrm{O}_{2}{ }^{-}$ production between cord and fourth-day blood samples in both VD- and ECS-delivered infants $(p<0.01)$. Zymosanstimulated samples showed higher values after VD than ECS, both in cord blood $(p<0.004)$ and on the fourth day of life $(p<0.006)$. A positive correlation was found between $\cdot \mathrm{O}_{2}{ }^{-}$release in zymosan-stimulated cord blood and
\end{abstract}

that found in the mothers at the beginning of labor $(r=$ $0.654 ; p<0.01)$, during labor $(r=0.721 ; p=0.008)$, and after delivery $(r=0.832 ; p=0.0008)$. A positive correlation was also found between $\mathrm{O}_{2}{ }^{-}$release and glutathione peroxidase on the fourth day $(r=0.709, p=0.014)$. The results of the present investigation demonstrate the role of peripartal events in modulating free radical release by polymorphonuclear leukocytes during the perinatal period. (Pediatr Res 36: 619-622, 1994)

$\quad$ Abbreviations
PMN, polymorphonuclear leukocyte
$\mathbf{O}_{2}^{-}$, superoxide anion
VD, vaginal delivery
ECS, elective cesarean section
GSH-Px, glutathione peroxidase
CAT, catalase
SOD, superoxide dismutase
US, unstimulated
ZS, zymosan-stimulated

Phagocyte function has been widely investigated in the newborn infant, and some impairment of oxidative burst activity has been demonstrated (1-3). Although contrasting results have been reported, there is presently little doubt that the most significant deficiencies in the phagocyte function in full-term and premature infants are related to chemoattractants, and that disturbances in free radical production due to reduced respiratory burst activity are slight, at least in nonstressed PMN $(3,4)$.

The current study was undertaken to detect whether the free radical release by PMN in whole blood of mothers and newborns could depend on the effect of plasma factors in relation to different modes of delivery.

Received March 22, 1993; accepted May 30, 1994.

Correspondence and reprint requests: Prof. Rodolfo Bracci, Cattedra di Neonatologia, Università di Siena, Via Paolo Mascagni, 46, 53100 Siena, Italy.

\section{METHODS}

Newborns. Seventy-two healthy, full-term newborn infants with Apgar scores greater than 9 at 5 min were examined. Their birth weights and gestational ages were $3321 \pm 472 \mathrm{~g}$ and $39 \pm 1.42 \mathrm{wk}$ (mean $\pm \mathrm{SD}$ ), respectively. Thirty-nine were born by VD and 33 by ECS without labor. Twenty-three of them were born to the mothers tested as reported below. Blood samples were obtained at birth, through the umbilical vein from separated placentas immediately after cord clamping, and on the fourth day of life from the peripheral vein of infants in whom blood collection was required for metabolic screening or routine analyses.

Mothers. A total of 23 healthy mothers aged $25 \pm 5 \mathrm{y}$ were investigated. Blood samples were taken from 14 of them undergoing VD at the beginning of labor, during 
labor, immediately after delivery, and $4 \mathrm{~d}$ after delivery. Nine mothers who underwent ECS without labor due to contracted pelvis, breech presentation, or previous cesarean section were tested before anesthesia, immediately after extraction of the fetus, and $4 \mathrm{~d}$ after delivery. The ECS group was comparable to the VD group in all other respects. All their neonates were evaluated at birth (cord blood) and on fourth day of life (peripheral vein). All mothers were tested for vaginal colonization of group B Streptococcus, Candida, Enterococcus, and Klebsiella, and neonates born to mothers with a positive culture, urinary tract infections, or fever were excluded from the study. Anesthesia for cesarean section was administered via premedication with $0.5 \mathrm{mg}$ of atropine given $30 \mathrm{~min}$ before delivery, a 3-min preoxygenation, induction of general anesthesia with $5 \mathrm{mg}$ of thiopentone per $\mathrm{kg}$ body weight followed by intubation (after $1 \mathrm{mg} / \mathrm{kg}$ succinylcholine), and ventilation with a $1: 1$ ratio of $\mathrm{N}_{2} \mathrm{O} / \mathrm{O}_{2}$.

Controls. Ten healthy, fertile, nonpregnant women were studied as the adult control group for the mothers and as the reference group for newborns. With the aim of evaluating the role of anesthesia, 11 fertile, nonpregnant women undergoing general (eight cases) or epidural (three cases) anesthesia for routine surgery for indications such as uterine fibroma, lipoma, and cysts, excluding cancer, were also tested before anesthesia and at the end of surgery to evaluate the possible inhibitory effect of anesthesia on $\mathrm{O}_{2}{ }^{-}$production.

The study was approved by the Human Ethics Committee of the Medical Faculty of the University of Siena. Informed consent was obtained from the parents of the newborn infants and from the adult subjects.

$\mathrm{O}_{2}{ }^{-}$generation. Blood samples from mothers and neonates were collected in heparinized tubes $(10 \mathrm{U} / \mathrm{mL})$ and were tested within $10 \mathrm{~min} \cdot \mathrm{O}_{2}{ }^{-}$generation was measured spectrophotometrically by the method of SOD-inhibitable reduction of ferricytochrome $c$, with and without opsonized zymosan stimulation of PMN in whole blood, according to the method of Bellavite et al. (5). Samples with and without zymosan were incubated at $37^{\circ} \mathrm{C}$ for $20 \mathrm{~min} . \mathrm{O}_{2}{ }^{-}$production was expressed as $\mathrm{nmol} /$ $10^{6}$ PMN. Care was taken to avoid methodologic variations throughout the experiment. All assays were performed in duplicate.

Antioxidant enzyme activities. In a subpopulation of 26 newborn infants (12 born by ECS, 14 by VD), red cell GSH-Px, CAT, glutathione reductase, and SOD activities were measured in duplicate in cord blood and in samples taken on the fourth day. The preparation of hemolysate from washed red cells and the assays of GSH-Px, CAT, and glutathione reductase were performed according to the methods summarized by Beutler (6). SOD was measured by the partially modified method of Beauchamp and Fridovich (7).

Statistics. The data are presented as means $\pm 1 \mathrm{SD}$. The analysis for within-group and between-group differences was determined by the two-tailed $t$ test for paired and grouped data, respectively. Simple linear regression anal- ysis was used to calculate statistical significance between $\mathrm{O}_{2}{ }^{-}$and antioxidant enzyme activities levels.

\section{RESULTS}

$\mathrm{O}_{2}^{-}$release in all samples taken as a whole (mothers, newborn infants, and controls; Tables 1 and 2). Significantly lower values were observed in US versus ZS blood samples $(p<0.001)$.

$\cdot \mathrm{O}_{2}^{-}$release in mothers (Table 1). In US samples, no significant differences were found between mothers undergoing VD and ECS, whereas these values were significantly lower in both groups compared with the controls. ZS samples showed significantly greater $\mathrm{O}_{2}{ }^{-}$release in mothers who underwent VD compared with those delivered by ECS. In comparison with the controls, values were significantly higher in the peripartal period in VD and lower in ECS. Four d after delivery, both groups showed significantly lower levels than the controls.

$\mathrm{O}_{2}{ }^{-}$release in total population of newborn infants. A comparison of results found in cord blood and on the fourth day of life showed a significant decrease in both US $\left(3.2 \pm 2.44\right.$ versus $0.68 \pm 0.7 \mathrm{nmol}^{\cdot} \mathrm{O}_{2}{ }^{-} / 10^{6} \mathrm{PMN}, p<$ $0.001)$ and $\mathrm{ZS}\left(14.3 \pm 11.6\right.$ versus $3.6 \pm 2.8 \mathrm{nmol} \cdot \mathrm{O}_{2}{ }^{-} / 10^{6}$ PMN, $p<0.001)$ samples.

$\mathrm{O}_{2}^{-}$release in neonates in relation to mode of delivery (Table 2). Neonates born by VD showed statistically significant, higher $\mathrm{O}_{2}{ }^{-}$values compared with those born by ECS. In US samples, spontaneously delivered infants showed higher $\mathrm{O}_{2}{ }^{-}$levels than those born by ECS only in cord blood. After zymosan stimulation, neonates born by VD had higher $\mathrm{O}_{2}{ }^{-}$levels than those born by ECS in both cord blood and on the fourth day of life. The comparison of results found in cord blood and on the fourth day of life showed a significant decrease in $\mathrm{O}_{2}{ }^{-}$levels in both groups of neonates.

The comparison between neonates and adult nonpregnant women (controls) showed a significantly lower ${ }^{\circ} \mathrm{O}_{2}^{-}$

Table 1. $\mathrm{O}_{2}{ }^{-}$release $\left(\mathrm{nmol} / 10^{6} \mathrm{PMN}\right)$ in $U S$ and $\mathrm{ZS}$ samples of maternal blood*

\begin{tabular}{llc}
\hline & US samples & ZS samples \\
\hline VD & & \\
$\quad$ Beginning of labor & $3.01 \pm 2.1^{\mathrm{a}}$ & $40.7 \pm 36.7^{\mathrm{i}}$ \\
$\quad$ During labor & $2.64 \pm 1.4^{\mathrm{b}}$ & $32.0 \pm 28.6^{1}$ \\
$\quad$ After delivery & $2.58 \pm 1.8^{\mathrm{c}}$ & $42.9 \pm 20.6^{\mathrm{m}}$ \\
$\quad$ 4th d & $1.82 \pm 0.9^{\mathrm{d}}$ & $9.2 \pm 7.4^{\mathrm{n}}$ \\
ECS & & \\
$\quad$ Before anesthesia & $3.19 \pm 1.2^{\mathrm{c}}$ & $16.8 \pm 5.2^{\mathrm{y}}$ \\
$\quad$ After extraction & $3.02 \pm 1.2^{\mathrm{f}}$ & $18.6 \pm 2.2^{\mathrm{q}}$ \\
4th d & $1.22 \pm 0.7^{\mathrm{g}}$ & $8.9 \pm 6.2^{\mathrm{r}}$ \\
Anesthesia control group & & \\
$\quad$ Before anesthesia & $4.11 \pm 2.32^{\mathrm{t}}$ & $27.62 \pm 14.87^{\mathrm{v}}$ \\
$\quad$ After anesthesia & $2.56 \pm 3.24^{\mathrm{u}}$ & $14.22 \pm 8.79^{\mathrm{z}}$ \\
Controls & $4.60 \pm 1.60^{\mathrm{h}}$ & $25.00 \pm 6.8^{\mathrm{s}}$ \\
\hline
\end{tabular}

* The data are presented as means $\pm 1 \mathrm{SD}$. The analysis for withingroup and between-group differences was determined by the two-tailed $t$ test for paired and grouped data, respectively. a $v s \mathrm{i}, \mathrm{b} v s \mathrm{l}, \mathrm{c} v s \mathrm{~m}, \mathrm{~d}$ $v s \mathrm{n}, \mathrm{e} v s \mathrm{y}, \mathrm{f} v s \mathrm{q}, \mathrm{g} v s \mathrm{r}, \mathrm{h} v s \mathrm{~s}: \mathrm{p}<0.001$; a $v s \mathrm{~d}$, i $v s \mathrm{~m}, \mathrm{l} v s \mathrm{~m}, \mathrm{~m} v s$ $\mathrm{n}, \mathrm{v} v s \mathrm{z}: p<0.01$; i $v s \mathrm{y}, \mathrm{m} v s \mathrm{q}, \mathrm{t} v s \mathrm{u}: p<0.05 ; \mathrm{a}, \mathrm{b}, \mathrm{c}, \mathrm{d}, \mathrm{e}, \mathrm{f}, \mathrm{g}, v s$ $\mathrm{h}: p<0.02 ; \mathrm{y}, \mathrm{q}, \mathrm{r}, v s$ s: $p<0.009$. 
Table 2. $\mathrm{O}_{2}^{-}$release (nmol/10 $\mathrm{PMN}$ ) in $\mathrm{US}$ and $\mathrm{ZS}$ blood samples of newborn infants*

\begin{tabular}{lcc}
\hline & US samples & ZS samples \\
\hline VD & & \\
Cord blood & $3.96 \pm 2.1^{\mathrm{a}}$ & $19.2 \pm 13.7^{\mathrm{e}}$ \\
4th d & $0.74 \pm 0.5^{\mathrm{b}}$ & $4.7 \pm 2.3^{\mathrm{f}}$ \\
ECS & & \\
Cord blood & $2.12 \pm 1.1^{\mathrm{c}}$ & $8.1 \pm 3.8^{\mathrm{g}}$ \\
4th d & $0.44 \pm 0.4^{\mathrm{d}}$ & $2.1 \pm 2.3^{\mathrm{h}}$ \\
Controls & $4.60 \pm 1.6^{\mathrm{i}}$ & $25.0 \pm 6.8^{1}$ \\
\hline
\end{tabular}

* The data are presented as means \pm 1 SD. The analysis for withingroup and between-group differences was determined by the two-tailed $t$ test for paired and grouped data, respectively. a $v s \mathrm{~b}, \mathrm{c} v s \mathrm{~d}$, e $v s \mathrm{f}, \mathrm{g}$ $v s$ h: $p<0.01$; a vs e, i vs l, b vs i: $p<0.002$; e vs $\mathrm{g}: p<0.004$; $\mathrm{f} v s$ h: $p<0.006$; a vs c: $p<0.05$; b, c, d vs i: $p<0.01$; $\mathrm{f}, \mathrm{g}, \mathrm{h} v s 1: p<0.001$

release in US samples of both groups of neonates on the fourth day of life. Neonates born by ECS showed lower $\mathrm{O}_{2}{ }^{-}$levels than controls in $\mathrm{ZS}$ samples both in cord blood and on the fourth day. Neonates born by VD presented lower $\mathrm{O}_{2}^{-}$levels than controls only on the fourth day of life.

$\mathrm{O}_{2}^{-}$release in newborns in relation to $\mathrm{O}_{2}^{-}$release in their mothers. The comparison between the $\mathrm{ZS} \cdot \mathrm{O}_{2}^{-}$release in mothers delivering spontaneously and that in cord blood of their respective neonates demonstrated a significant positive correlation. This correlation becomes more significant as labor progresses (at the beginning of labor, $r=0.654$ and $p<0.01$; during labor, $r=0.721$ and $p=0.008$; and immediately after delivery, $r=0.832$ and $p=0.0008)$.

$\mathrm{O}_{2}{ }^{-}$release in nonpregnant women undergoing general or epidural anesthesia. A lower $\mathrm{O}_{2}{ }^{-}$production was observed after anesthesia than before anesthesia (Table 1).

Antioxidant red cell enzyme activities at birth and on the fourth day of life in a subpopulation of 26 newborn infants (Table 3). Significantly higher GSH-Px levels were observed on the fourth day of life than in cord blood. No significant correlation was observed between $\mathrm{O}_{2}^{-}$release and red cell antioxidant enzyme activities (GSHPx, SOD, and CAT) in cord blood. A significant positive correlation was found between $\mathrm{O}_{2}{ }^{-}$release and GSH-Px on the fourth day $(r=0.709, p=0.014)$, whereas a significant negative correlation was seen between $\mathrm{O}_{2}{ }^{-}$ release and CAT activity $(r=-0.631, p=0.036)$. No other significant correlation was found between red cell enzyme activities and $\mathrm{O}_{2}{ }^{-}$release.

Table 3. Antioxidant red cell enzyme activities at birth and on the fourth day of life in a subpopulation of 26 newborn infants*

\begin{tabular}{lcc}
\hline \multicolumn{1}{c}{ Enzyme activities } & Cord blood & 4th d blood \\
\hline SOD (IU/ $\mu \mathrm{g} \mathrm{Hb})$ & $1.38 \pm 0.15$ & $1.31 \pm 0.13$ \\
GSH-Px (IU/g Hb) & $11.86 \pm 1.54^{\mathrm{a}}$ & $14.95 \pm 3.42^{\mathrm{b}}$ \\
Glutathione reductase (IU/g Hb) & $5.12 \pm 1.53$ & $5.98 \pm 1.62$ \\
CAT (IU/g Hb) & $10.96 \pm 1.71$ & $11.10 \pm 1.96$ \\
\hline
\end{tabular}

\footnotetext{
* The data are presented as means \pm 1 SD. a $v s$ b: $p<0.02$ (paired data).
}

\section{DISCUSSION}

The results of the present investigation demonstrate the role of peripartal events in modulating free radical release by the blood cells during the perinatal period. Because a highly significant difference has been found between cord blood and blood of 4-d-old neonates, it is feasible that intrauterine factors modulate $\mathrm{O}_{2}{ }^{-}$release by PMN.

The hypothesis of an important role of plasma factors is confirmed by the data obtained in the mothers, which demonstrate that the mode of delivery is associated with differences in $\mathrm{O}_{2}{ }^{-}$release.

Our results are in disagreement with previously reported data demonstrating that ZS oxygen consumption, hexosemonophosphate shunt activity, and quantitative nitroblue tetrazolium dye reduction were lower in cord blood PMN from infants delivered vaginally than in those delivered by ECS (8). However, the study by Frazier et al. (8) was carried out in isolated leukocytes, whereas our investigation was performed on whole blood. Because plasma factors may modulate phagocyte function, it is possible that the isolation of PMN substantially alters the conditions of phagocyte activation. The finding of lower values in ZS samples from spontaneously delivered infants compared with adult controls is in agreement with the findings of Ambruso et al. (9).

It is important to note that, although the values of $\mathrm{O}_{2}{ }^{-}$ production in US blood samples from mothers undergoing either VD or ECS did not differ, the $\mathrm{O}_{2}{ }^{-}$values in the same subjects after zymosan were significantly higher in VD than ECS. The significant positive correlation between $\mathrm{O}_{2}{ }^{-}$release after zymosan stimulation in cord blood and that found in the mother is of considerable interest. The $r$ coefficient of this correlation increased progressively from the beginning of labor to the end of delivery.

The $\mathrm{O}_{2}^{-}$release in the maternal samples was also significantly higher after VD than after ECS. The difference between the two modes of delivery was also evident in the neonates. In particular, newborn infants delivered by ECS without labor showed significantly lower $\mathrm{O}_{2}{ }^{-}$ production after stimulation by zymosan and in basal conditions. Samples to which zymosan was added still showed significant differences between infants born by ECS and those born by $\mathrm{VD}$, even after $4 \mathrm{~d}$, when $\mathrm{O}_{2}{ }^{-}$ production was greatly reduced compared with that found in the cord blood.

The results of the determination of $\mathrm{O}_{2}{ }^{-}$release during anesthesia, performed in women undergoing surgery for indications other than ECS, demonstrated lower $\mathrm{O}_{2}{ }^{-}$ release after anesthesia than that measured before anesthesia. Therefore, it cannot be ruled out that anesthesia or surgery plays a role in suppressing $\mathrm{O}_{2}{ }^{-}$release. However, the differences that we observed in $\mathrm{O}_{2}{ }^{-}$release between VD and ECS are independent of anesthesia, because the comparison was made between mothers during labor and mothers before anesthesia for ECS. Fur- 
thermore, the importance of possible plasma factors is stressed by the significant correlation between $\mathrm{O}_{2}{ }^{-}$release in mothers delivering vaginally and that in the cord blood samples of their neonates.

The differences in plasma hormone levels seen in ECS and VD might play a role in the differences in PMN activation (10). However, the results of previous investigations demonstrating variations in interleukin levels during labor $(11,12)$ and significant differences in IL-1 and IL- 6 between cord blood of infants delivered by different modes (13) suggest that cytokine production during labor may be the most important factor. Because interleukins have a key role in the activation of the PMN burst (14), the agreement between the differences in IL-1 and IL-6 levels in cord blood and the differences in $\mathrm{O}_{2}{ }^{-}$ release suggest that interleukins may be one of the factors involved in the modulation of phagocyte function in the first hours of life.

Our recent observations demonstrated increased IL-1 $\beta$ and IL- 6 during labor and immediately after delivery in mothers who had VD compared with mothers who had ECS. A significant positive correlation was found between values of IL- 6 plasma concentrations and $\mathrm{O}_{2}{ }^{-}$ release (15).

The significant increase in GSH-Px on the fourth day of life and the positive correlation between $\mathrm{O}_{2}{ }^{-}$release and erythrocyte GSH-Px in the same samples suggest that GSH-Px can increase in the red cell as a result of the toxic oxygen species deriving from the activated PMN oxidative burst (16-18). Therefore, the possibility that phagocyte activity may play a role in the increase in GSH-Px activity observed in the first days of life (19) cannot be ruled out.

The significance of negative correlation between $\mathrm{O}_{2}{ }^{-}$ release and CAT remains unknown.

Although the clinical significance of changes in $\mathrm{O}_{2}{ }^{-}$ release as a consequence of VD is unclear, the modifications reported in this study suggest that plasma factors modulate PMN activation in the peripartal period and during the first few days of life. In particular, it is evident that the mechanism of delivery per se constitutes a factor in the activation of PMN free radical release.

\section{REFERENCES}

1. Cocchi P, Marianelli L 1967 Phagocytosis and intracellular killing of Pseudomonas aeruginosa in premature infants. Helv Paediatr Acta 22:110-118

2. Marodi L, Leijh PCJ, van Furth R 1984 Characteristics and functional capacities of human cord blood granulocytes and monocytes. Pediatr Res 18:1127-1131

3. Gahr M, Blanke R, Speer CP 1985 Polymorphonuclear leukocyte function in term and preterm newborn infants. Biol Neonate 48:15-20

4. Conly ME, Speert DP 1991 Human neonatal monocyte-derived macrophages and neutrophils exhibit normal nonopsonic and opsonic receptor-mediated phagocytosis and superoxide anion production. Biol Neonate 60:361-366

5. Bellavite P, Dri P, Della Bianca V, Serra MC 1983 The measurement of superoxide anion production by granulocytes in whole blood. A clinical test for the evaluation of phagocyte function and serum opsonic capacity. Eur $J$ Clin Invest 13:363-368

6. Beutler E 1975 Red cell metabolism. A manual of biochemical methods. 2nd Ed. Grune \& Stratton, New York

7. Beauchamp CO, Fridovich I 1973 Isozymes of superoxide dismutases form wheat germ. Biochim Biophys Acta 317:50-64

8. Frazier JP, Cleary TG, Pickering LK, Kohl S, Ross PJ 1982 Leukocyte function in healthy neonates following vaginal and cesarean section deliveries. J Pediatr 101:269-272

9. Ambruso DR, Bentwood B, Henson PM, Johnston Jr RB 1984 Oxidative metabolism of cord blood neutrophils: relationship to content and degranulation of cytoplasmatic granules. Pediatr Res 18:1148-1153

10. Bracci R, Bagnoli F, Bruchi S 1988 Neonatal endocrine function in relation to the mode of delivery. In: Cosmi EV, Di Renzo GC (eds) Proceedings of XI European Congress of Perinatal Medicine. Harwood Academic Publishers, Chur, Switzerland, pp 344-355

11. Romero R, Brody DT, Oyarzun E, Mazor M, Wu YK, Hobbins JC, Durum SK, 1989 Infection and labor. III. Interleukin-1: a signal for the onset of parturition. Am J Obstet Gynecol 160:1117-1123

12. Romero R, Avila C, Santhanam U, Sehgal PB 1990 Amniotic fluid interleukin 6 in preterm labor. J Clin Invest 85:1392-1400

13. Miller LC, Isa S, Lo Preste G, Schaller JG, Dinarello CA 1990 Neonatal interleukin- $1 \beta$, interleukin- 6 , and tumor necrosis factor: cord blood levels and cellular production. J Pediatr 117:961-965

14. Morel F, Doussiere J, Vignais PV 1991 The superoxide-generating oxidase of phagocytic cells. Physiological, molecular and pathological aspects. Eur J Biochem 201:523-546

15. Buonocore G, Luzzi E, Gioia D, De Filippo M, Picciolini E, Bocci V, Bracci R 1993 Interleukin-1 $\beta$, interleukin-6, tumor necrosis factor- $\alpha$, interferon- $\gamma$, granulocyte-macrophage-colony stimulating factor plasma levels and superoxide anion generation in mothers and newborns in relation to mode of delivery. Eur J Pediatr 11:951(abstr)

16. Vives Corrons JL, Pujades MA, Colomer D 1988 Increase of enzyme activities following the in vitro peroxidation of normal human red blood cells. Enzyme 39:1-7

17. Winterbourn CC, Stern A 1987 Human red cells scavenge extracellular hydrogen peroxide and inhibit formation of hypochlorous acid and hydroxyl radical. J Clin Invest 80:1486-1491

18. Weiss SJ 1982 Neutrophil-mediated methemoglobin formation in the erythrocyte. The role of superoxide and hydrogen peroxide. J Biol Chem 257:29472953

19. Bracci R, Buonocore G, Talluri B, Berni S 1988 Neonatal hyperbilirubinemia. Evidence for a role of the erythrocyte enzyme activities involved in the detoxification of oxygen radicals. Acta Paediatr Scand 77:349-356 